\title{
Duopoly Dynamics with a Barrier to Entry
}

Jaap H. Abbring ${ }^{1}$

Jeffrey R. Campbel/2

' Vrije Universiteit Amsterdam, and Tinbergen Institute;

2 Federal Reserve Bank of Chicago, and NBER. 


\section{Tinbergen Institute}

The Tinbergen Institute is the institute for economic research of the Erasmus Universiteit Rotterdam, Universiteit van Amsterdam, and Vrije Universiteit Amsterdam.

Tinbergen Institute Amsterdam

Roetersstraat 31

1018 WB Amsterdam

The Netherlands

Tel.: $\quad+31(0) 205513500$

Fax: $\quad+31(0) 205513555$

Tinbergen Institute Rotterdam

Burg. Oudlaan 50

3062 PA Rotterdam

The Netherlands

Tel.: $\quad+31(0) 104088900$

Fax: $\quad+31(0) 104089031$

Most TI discussion papers can be downloaded at http:/ /www.tinbergen.nl. 


\title{
Duopoly Dynamics with a Barrier to Entry*
}

\author{
Jaap H. Abbring ${ }^{\dagger} \quad$ Jeffrey R. Campbell ${ }^{\ddagger}$
}

April, 2007

\begin{abstract}
This paper considers the effects of raising the cost of entry for a potential competitor on infinite-horizon Markov-perfect duopoly dynamics with ongoing demand uncertainty. All entrants serving the model industry incur sunk costs, and exit avoids future fixed costs. We focus on the unique equilibrium with last-in first-out expectations: A firm never exits leaving behind an active younger rival. We prove that raising a second producer's sunk entry cost in an industry that supports at most two firms reduces the probability of having a duopoly but increases the probability that some firm will serve the industry. Numerical experiments indicate that a barrier to entry's quantitative relevance depends on demand shocks' serial correlation. If they are not very persistent, the direct entry-deterring effect of a barrier to a second firm's entry greatly reduces the average number of active firms. The indirect entry-encouraging effect does little to offset this. With highly persistent demand shocks, the direct effect is small and the barrier to entry has no substantial effect on the number of competitors. This confirms Carlton's (2004) assertion that the effects of a barrier depend crucially on industry dynamics that two-stage "short run/long run" models capture poorly.
\end{abstract}

${ }^{*}$ We are grateful to Allan Collard-Wexler and Meredith Crowley for their insightful comments. The National Science Foundation supported this research through Grant 0137042 to the NBER, and De Jonge Akademie of the Royal Netherlands Academy of Arts and Sciences supported this research through a travel grant. A replication file is available at http://www.nber.org/ jrc/lifo

${ }^{\dagger}$ VU University Amsterdam and Tinbergen Institute. E-mail:jabbring@feweb.vu.nl

${ }^{\ddagger}$ Federal Reserve Bank of Chicago and NBER. E-mail: jcampbell@frbchi.org JEL Codes L13, L41

Keywords: LIFO, FIFO, Sunk costs, Markov-perfect equilibrium, Competition policy 


\section{Introduction}

This paper determines the effects of raising a late entrant's sunk cost in a duopoly version of the industry dynamics model presented in a companion paper (Abbring and Campbell, 2006). Demand evolves stochastically; entry possibly requires paying a sunk cost; and continued operation incurs fixed costs. The wish to avoid these per-period fixed costs in markets that are no longer profitable motivates firms to exit. We assume that all participants rationally expect exit decisions to follow a last-in first-out pattern. That is, no firm produces after the exit of an older competitor. Two considerations motivate this focus. First, it embodies (in an extreme way) the widespread observation that young firms exit more frequently than their older counterparts. Second, the last-in first-out restriction favors incumbents; so we expect them to deter entry and promote exit by shifting equilibrium expectations in this direction with any available means.

Abbring and Campbell (2006) prove that there exists an essentially unique Markov-perfect equilibrium with last-in first-out expectations, and they provide a simple procedure for its calculation. These results allow us to compare duopoly dynamics with different sunk costs of entry. We first provide an analytic characterization of the effects of barriers to entry. Raising a second entrant's sunk cost reduces the probability of two firms operating, but increases the probability that some firm will serve the industry. The first effect is the expected entry deterrence. The second reflects the positive influence of barriers to entry on the value of being a monopolist, and it is familiar from the static analysis of patents and innovation. We also show that raising the second entrant's sunk costs reduces average entry and exit rates. In this specific sense, barriers to entry stabilize industry structure.

These qualitative results say nothing about a barrier to entry's quantitative importance, so we complement them with a wide range of numerical examples. We find that when demand shocks are not very persistent, a barrier to entry substantially lowers the average number of firms serving the industry. The entry-encouraging effect is small and does little to offset the direct deterrent effect. Raising the persistence of demand dramatically changes this. For a wide range of specifications with persistent shocks, we find that a sizeable barrier to a second firm's entry has only trivial effects on the number of active firms. The entry-encouraging effect remains quantitatively unimportant and does not explain this result. Rather, highly persistent demand makes the direct deterrent effect small. We do not explore the welfare implications of a barrier to entry in detail. However, our numerical results suggest that even a large barrier to entry entails little welfare loss in the empirically-relevant case with highly persistent demand shocks. 
The term "barrier to entry" has a rich and confusing history. McAfee, Mialon, and Williams (2004) review the many definitions proposed for it and conclude that none of them are useful for antitrust analysis. They offer a new definition:

An economic barrier to entry is a cost that must be incurred by a new entrant and that incumbents do not or have not had to incur.

The barrier to entry we consider satisfies this. Carlton (2004) asserts that the effects of such a barrier depend crucially on the industry's medium-run dynamics, so two-stage "short run/long run" models capture them poorly. This paper's results confirm and refine this point: The positive effects of increasing a second entrant's sunk costs substantially depend on the stochastic rule governing the evolution of demand.

Most of this paper's analysis assumes a last-in first-out (LIFO) pattern for entry and exit. In the companion paper, we demonstrate that the Markov-perfect equilibrium satisfying this restriction can be viewed as an approximation for a model with a learning curve. In the learning-curve model, firms' fixed costs decline as they age and no firm exits while leaving behind a higher cost rival. Cabral (1993) uses this latter restriction to select a "natural" equilibrium. This approximation result indicates that this paper's analysis most naturally applies to industries with technologies that favor experienced firms.

Models of Schumpetarian economic growth assume that technology favors younger firms, so this situation also merits analysis. For this, we examine a version of our model in which the younger firm's continuation decision comes first. We prove the existence of an equilibrium with first-in first-out expectations, and this is the unique equilibrium in which a higher demand state never yields fewer active firms. In this sense, the equilibrium is also "natural". The qualitative effects of raising a barrier to entry in this environment are identical to those from the case with LIFO expectations. Unfortunately, the FIFO analysis requires demand to follow a particular stochastic process.

The remainder of this paper proceeds as follows. The next section presents the model's primitives and derives the effects of barriers to entry for a specific example with a penciland-paper equilibrium solution. Section 3 presents the analysis of the general model, and Section 4 examines the model's FIFO version. Section 5 explains the relationship between our work and existing papers on entry deterrence, competitive industry dynamics, and the computational analysis of competition policy. Section 6 contains some concluding remarks. 


\section{The Model}

The model consists of a single duopolistic market in discrete time $t \in\{0,1, \ldots\}$. There is a large number of firms that are potentially active in the market. We index these firms with $\mathbb{N}$. At time $0, N_{0}=0$ firms are active. Entry and subsequent exit of firms determines the number of active firms $N_{t}$ in each later period. At most two firms can be active in the industry at any given time. The number of consumers in the market, $C_{t}$, evolves stochastically according to a first-order Markov process on the interval $[\hat{C}, \check{C}]$.

The sequence of events and actions within a period begins with the inherited values of $N_{t}$ and $C_{t-1}$. First, all participants observe the realization of $C_{t}$. Then, all active firms receive profits equal to $\left(C_{t} / N_{t}\right) \times \pi\left(N_{t}\right)-\kappa$. Here, each firm serves $C_{t} / N_{t}$ customers, and $\pi\left(N_{t}\right)$ is the producer surplus earned from each one. We assume that $\pi(1)>\pi(2) / 2$, so that entry reduces an incumbent firm's profits. The term $\kappa>0$ represents fixed costs of production.

After serving the market, active firms decide whether they will remain so. These decisions are sequential and begin with the oldest firm. In particular, if two firms are currently active in the market $\left(N_{t}=2\right)$ the older duopolist will decide first on continuation and the younger duopolist follows. For future reference, we introduce notation for the firm's rank in this sequence of exit decisions: If firm $i$ is active in period $t$, then $R_{t}^{i}=1$ if it is either a monopolist or the older duopolist; and $R_{t}^{i}=2$ if it is the younger duopolist. Exit is costless but irreversible and allows the firm to avoid future periods' fixed production costs.

If the continuation decisions do not commit two firms to serving the market, then the firm with the smallest name $(i)$ that has also not yet had an opportunity to enter makes an entry decision. The cost of entry potentially depends on the number of firms already committed to serving the market in the next period. We denote the entry cost for a firm that would be the oldest among next period's active firms with $\varphi(1)$, and the same cost for a firm that would be the youngest next period equals $\varphi(2)$. The payoff to staying out of the industry is always zero, because a firm with an entry opportunity cannot defer the option. If firm $i$ chooses to enter an otherwise empty industry, then firm $i+1$ chooses between staying out of the industry and entering with $R_{t+1}^{i+1}=2$. Otherwise, the period ends. We specified the entry technology in this way to capture "free entry" within a game-theoretic environment, which requires us to name every player and specify their possible actions and payoffs. ${ }^{1}$ Both active firms' and potential entrants' decisions maximize their expected stream of profits discounted

\footnotetext{
${ }^{1}$ The restriction to markets with at most two firms can be formalized in the more general model of Abbring and Campbell (2006) by either setting the entry cost $\varphi\left(R^{\prime}\right)$ for a firm with potential next period's rank $R^{\prime} \geq 3$ to a very large value or by setting the producer's surplus $\pi\left(N^{\prime}\right)$ in a market with $N^{\prime} \geq 3$ firms to 0 .
} 
with $\beta<1$. We assume that $\varphi(2) \geq \varphi(1) \geq 0$. If $\varphi(2)>\varphi(1)$, we say that a second entrant faces a barrier to entry (relative to a first entrant). We do not model the actions that incumbents or policy makers take to impose these costs.

\subsection{Markov-perfect equilibrium}

We choose as our equilibrium concept symmetric Markov-perfect equilibrium. When firm $i$ decides whether to stay or exit, $N_{t}-R_{t}^{i}$ (the number of active firms following it in the sequence), $C_{t}$, and $R_{t+1}^{i}$ (its rank in the next period's sequence of active firms) are available and payoff-relevant. Collect these into $H_{i t} \equiv\left(N_{t}-R_{t}^{i}, C_{t}, R_{t+1}^{i}\right)$. Similarly, the payoffrelevant state to a potential entrant is $H_{i t} \equiv\left(C_{t}, R_{t+1}^{i}\right)$. Note that $H_{i t}$ takes its values in $\mathcal{H}_{S} \equiv\{0,1\} \times[\hat{C}, \check{C}] \times\{1,2\}$ for firms active in period $t$ and in $\mathcal{H}_{E} \equiv[\hat{C}, \check{C}] \times\{1,2\}$ for potential entrants. Here and below, we use $S$ and $E$ to denote survivors and entrants.

A Markov strategy for firm $i$ is a pair $\left(A_{S}^{i}\left(H_{S}\right), A_{E}^{i}\left(H_{E}\right)\right)$ for each $H_{S} \in \mathcal{H}_{S}$ and $H_{E} \in$ $\mathcal{H}_{E}$. These represent the probability of being active in the next period given that the firm is currently active $\left(A_{S}^{i}(\cdot)\right)$ and given that the firm has an entry opportunity $\left(A_{E}^{i}(\cdot)\right)$. A symmetric Markov-perfect equilibrium is a subgame-perfect equilibrium in which all firms follow the same Markov strategy.

When firms use Markov strategies, the payoff-relevant state variables determine an active firm's expected discounted profits at any node of the game tree. We denote these at the moment of the continuation decision with $v\left(H_{S}\right)$. In a Markov-perfect equilibrium, this function satisfies the Bellman equation

$$
v\left(H_{S}\right)=\max _{a \in[0,1]} a \beta \mathbb{E}\left[\frac{C^{\prime}}{N^{\prime}} \pi\left(N^{\prime}\right)-\kappa+v\left(H_{S}^{\prime}\right) \mid H_{S}\right] .
$$

Here and throughout, we adopt conventional notation and denote the variable corresponding to $X$ in the next period with $X^{\prime}$. In Equation (1), the expectation of $N^{\prime}$ is calculated using all firms' strategies conditional on the particular firm of interest choosing to be active.

Although firms make their continuation and entry decisions sequentially, the game's infinite horizon removes the standard argument for uniqueness of subgame perfect equilibrium. Abbring and Campbell (2006) show that uniqueness of equilibrium can be restored by focusing only on Markov-perfect symmetric equilibria in which an older firm's first-mover advantage translates into longevity. By definition, firms in such an equilibrium follow a common last-in first-out (LIFO) strategy.

Definition 1. A LIFO strategy is a pair of functions $\left(A_{S}, A_{E}\right)$ such that $A_{S}\left(H_{S}\right) \in\{0,1\}$, $A_{E}\left(H_{E}\right) \in\{0,1\}$, and $A_{S}\left(1, C, R^{\prime}\right) \geq A_{S}\left(0, C, R^{\prime}\right)$. 
If all firms follow a common LIFO strategy and the market is served by two firms, then the youngest of these two firms will decide to exit whenever the oldest does:

$$
A_{S}(1, C, 1)=0 \Rightarrow A_{S}(0, C, 1)=0 .
$$

Constructing a Markov-perfect equilibrium in a LIFO strategy is straightforward. Consider the decisions of a firm entering with one firm already committed to produce in the next period, that is with (potential) rank 2. This firm will produce no longer than the older firm and will not experience further entry of competitors during its time in the market, so the Bellman equation governing $v(\cdot, \cdot, 2)$ corresponds to a familiar non-strategic exit decision. This Bellman equation obviously has a unique fixed point, and we choose its associated optimal decision rule to form $A_{S}(0, C, 2)$ and $A_{E}(C, 2)$. If the firm is indifferent between activity and inactivity at some value of $C$, we choose the rule that defaults to inactivity. With this complete, we can consider the problem of a firm with rank 1. Maximizing its profit requires only expectations about the entry and exit of a firm with rank 2 , which are already in hand. Thus, standard dynamic programming arguments yield the unique value function satisfying the Bellman equation. With this, we can set $A_{S}(0, C, 1), A_{S}(1, C, 1)$, and $A_{E}(C, 1)$ to the unique optimal decision rule that defaults to inactivity.

The construction of this equilibrium suggests that it is the only one in a LIFO strategy that defaults to inactivity. We present a formal proof of this in Abbring and Campbell (2006, Proposition 2). As we mentioned in this paper's introduction, we find the restriction to LIFO strategies natural for the problem at hand, because it embodies in an extreme form the empirical regularity that young firms exit more frequently than their older counterparts and because these expectations make entry less profitable by placing incumbents in a privileged position. It is also powerful enough to select an essentially unique Markov-perfect equilibrium, so we impose it on our analysis.

\subsection{A Pencil-and-Paper Example}

If we assume that $C_{t}=C_{t-1}$ with probability $1-\lambda$ and that it equals a draw from a uniform distribution on $[\hat{C}, \check{C}]$ with the complementary probability, then we can calculate the model's equilibrium value functions and decision rules with pencil and paper. Before proceeding, we examine this special case to illustrate the model's moving parts. To ensure that the equilibrium dynamics are not trivial, we assume that no firm will serve the industry 
if demand is low enough and that two firms will serve the industry if it is sufficiently high. ${ }^{2}$

To begin, consider an incumbent firm with rank 2. In an equilibrium in a LIFO strategy, its profit equals $(C / 2) \pi(2)-\kappa$. It will earn this until the next time that $C_{t}$ changes, at which point demand will be statistically independent of its current value. These facts imply that this firm's value function is piecewise linear in $C$.

$$
v(0, C, 2)= \begin{cases}0 & \text { if } C \leq \underline{C}_{2}, \\ \beta \frac{(1-\lambda)\left(\frac{C}{2} \pi(2)-\kappa\right)+\lambda \widetilde{v}(0,2)}{1-\beta(1-\lambda)} & \text { if } C>\underline{C}_{2},\end{cases}
$$

where

$$
\widetilde{v}(0,2)=\frac{1}{2}\left(\frac{\hat{C}+\check{C}}{2}\right) \pi(2)-\kappa+\int_{\hat{C}}^{\check{C}} \frac{v\left(0, C^{\prime}, 2\right)}{(\check{C}-\hat{C})} d C^{\prime} .
$$

Here, $\widetilde{v}(0,2)$ is the firm's average continuation value given a new draw of $C_{t}$ and $C_{2}$ is the largest value of $C$ that satisfies $v(0, C, 2)=0$. Optimality requires the firm to exit if $C<\underline{C}_{2}$. This value function is monotonic in $C$, so there is a unique entry threshold $\bar{C}_{2}$ that equates the continuation value with the entry cost. Thus, a second duopolist enters whenever $C_{t}$ exceeds $\bar{C}_{2}$ and exits if it subsequently falls at or below $\underline{C}_{2}$.

Next, consider the problem of an incumbent with rank 1 . If this firm is currently a monopolist, it expects to remain so until $C_{t}>\bar{C}_{2}$; and if it is currently a duopolist, it expects to become a monopolist when $C_{t}$ falls below $\underline{C}_{2}$. This firm's value function is also piecewise linear. If the firm begins the period as the sole incumbent, it is

$$
v(0, C, 1)= \begin{cases}0 & \text { if } C \leq \underline{C}_{1} \\ \beta \frac{(1-\lambda)(C \pi(1)-\kappa)+\lambda \tilde{v}(0,1)}{1-\beta(1-\lambda)} & \text { if } \underline{C}_{1}<C \leq \bar{C}_{2}, \\ \beta \frac{(1-\lambda)\left(\frac{C}{2} \pi(2)-\kappa\right)+\lambda \tilde{v}(1,1)}{1-\beta(1-\lambda)} & \text { if } C>\bar{C}_{2} ;\end{cases}
$$

and if it begins as one of two incumbents it equals

$$
v(1, C, 1)= \begin{cases}0 & \text { if } C \leq \underline{C}_{1}, \\ \beta \frac{(1-\lambda)(C \pi(1)-\kappa)+\lambda \widetilde{v}(0,1)}{1-\beta(1-\lambda)} & \text { if } \underline{C}_{1}<C \leq \underline{C}_{2}, \\ \beta \frac{(1-\lambda)\left(\frac{C}{2} \pi(2)-\kappa\right)+\lambda \tilde{v}(1,1)}{1-\beta(1-\lambda)} & \text { if } C>\underline{C}_{2} .\end{cases}
$$

The exit threshold $\underline{C}_{1}$ is the greatest value of $C$ such that $v(0, C, 1)=0$, and the average continuation values following a change in $C_{t}$ for a monopolist and a duopolist are

\footnotetext{
${ }^{2}$ Sufficient conditions for these two properties are $(1-\lambda)[\hat{C} \pi(1)-\kappa]+\lambda \frac{\frac{\hat{C}+\check{C}}{2} \pi(1)-\kappa}{1-\beta}<0$ and $\beta\left[\frac{(1-\lambda)\left(\frac{\check{C}}{2} \pi(2)-\kappa\right)+\frac{\lambda}{1-\beta}\left(\frac{1}{2} \frac{\check{C}+\hat{C}}{2} \pi(2)-\kappa\right)}{1-\beta(1-\lambda)}\right]>\varphi(2)$.
} 

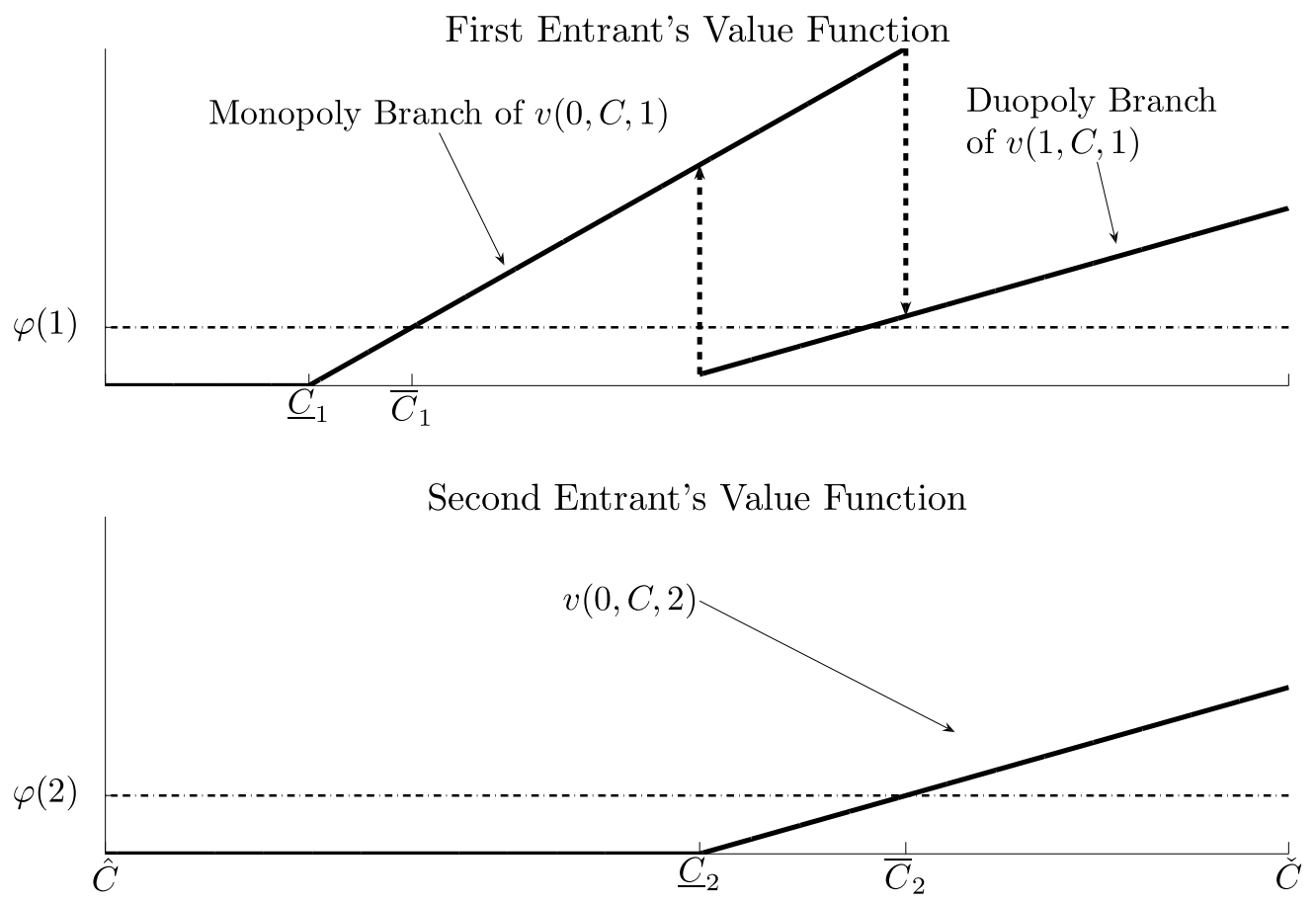

Figure 1: Equilibrium in the Pencil-and-Paper Example

$$
\begin{aligned}
\widetilde{v}(0,1) & =\left(\frac{\hat{C}+\check{C}}{2}\right) \pi(1)-\kappa+\int_{\hat{C}}^{\check{C}} \frac{v\left(0, C^{\prime}, 1\right)}{(\check{C}-\hat{C})} d C^{\prime}, \\
\widetilde{v}(1,1) & =\frac{1}{2}\left(\frac{\hat{C}+\check{C}}{2}\right) \pi(2)-\kappa+\int_{\hat{C}}^{\check{C}} \frac{v\left(1, C^{\prime}, 1\right)}{(\check{C}-\hat{C})} d C^{\prime} .
\end{aligned}
$$

This value function does not always increase with $C$, because slightly raising $C$ from $\bar{C}_{2}$ induces entry by the second firm and causes both current profits and the continuation value to discretely drop. Nevertheless we know that they drop to a value above $\varphi(1)$, because at this point the second firm chooses to enter. Hence, it is still possible to find a unique entry threshold $\bar{C}_{1}$ that equates the value of entering with rank 1 to the cost of doing so.

Figure 1 visually represents the equilibrium. In each panel, $C$ runs along the horizontal axis. The vertical axis gives the value of a firm at the time that entry and exit decisions are made. The top panel plots the value of a firm with rank 1 , while the bottom plots the 

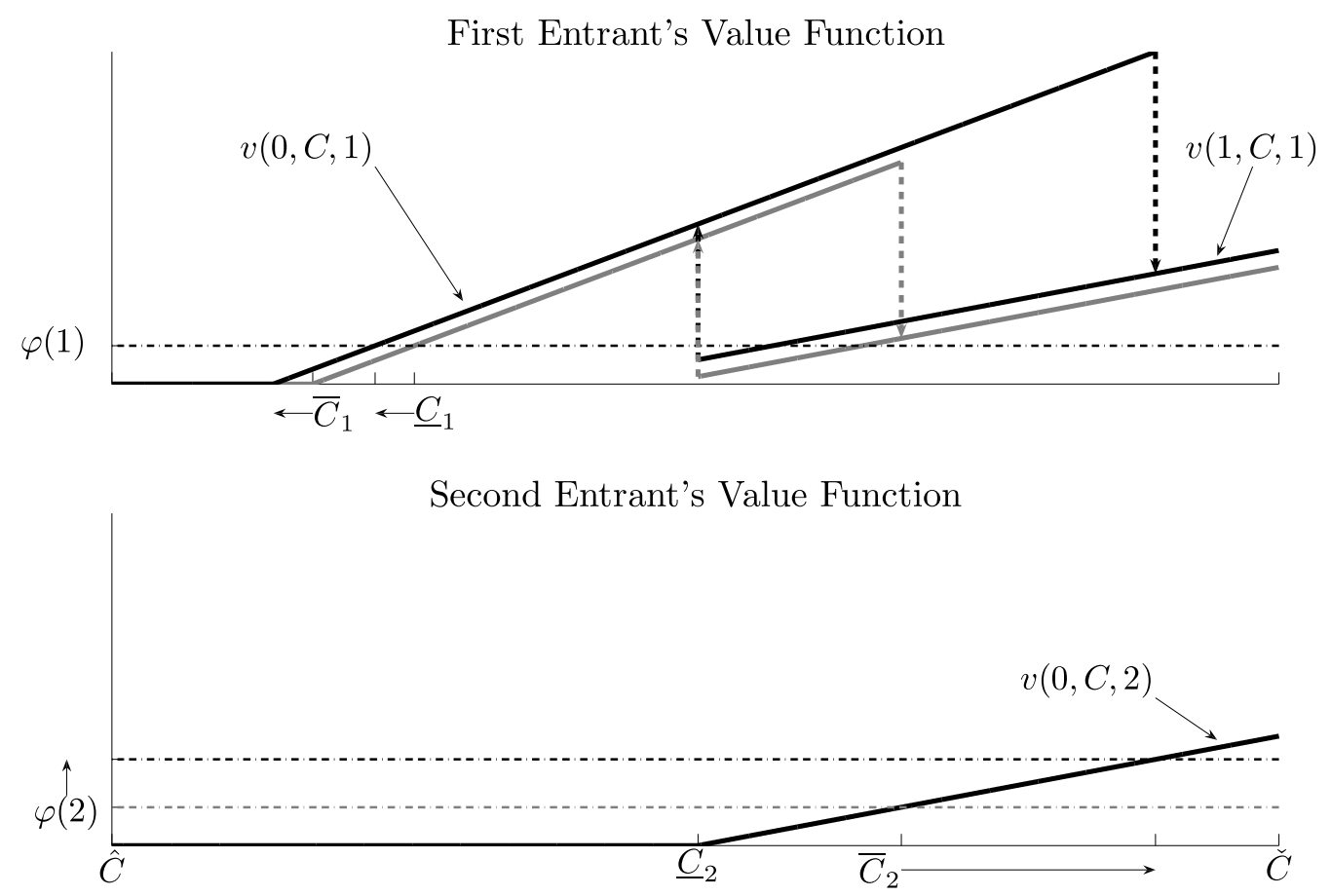

Figure 2: Effects of Raising $\varphi(2)$ in the Pencil-and-Paper Example

value for a competitor with rank 2. Both panels use the same vertical scale. The value of a duopolist with rank 2 equals zero for $C<\underline{C}_{2}$, and thereafter increases linearly with $C$. The entry threshold $\bar{C}_{2}$ equates this value with $\varphi(2)$. The value of an older firm with rank 1 has two branches. The upper monopoly branch gives the value of a monopolist expecting no further entry. If $C$ increases above $\bar{C}_{2}$ and thus induces entry, the firm's value drops to the lower duopoly branch. This has the same slope as the value function in the lower panel. Its intercept is higher, because the incumbent expects eventually to become a monopolist the first time that $C$ passes below $\underline{C}_{2}$. When this occurs, the firm's value returns to the monopoly branch. The entry and exit thresholds for this firm occur where the monopoly branch intersects $\varphi(1)$ and 0 .

Now turn to the effects of increasing $\varphi(2)$ on this duopoly's dynamics. Figure 2 illustrates this exercise. If a second firm actually enters the market, then the entry cost has no impact on that firm's optimal exit decision or value function. The value function in the bottom panel is monotonic in $C$, so raising $\varphi(2)$ directly increases $\bar{C}_{2}$. In this sense, raising $\varphi(2)$ 
directly deters entry. The impact of this on an incumbent's value is clear. Both branches of the value function shift up, from the grey to the solid black, and this lowers both $\bar{C}_{1}$ and $\underline{C}_{1}$. Intuitively, these changes lower the probability that either zero or two firms will serve the industry.

\section{Barriers to Entry}

Incumbents' attempts to deter contestants' entry occupy a central place in dynamic industrial organization. In this section, we characterize the effects of raising $\varphi(2)$ for given $\varphi(1)$. Actions available to a real-world incumbent for increasing $\varphi(2)$ include bidding-up the price of fixed inputs, litigation, and purchases of legal entry restrictions. We do not explicitly model the incumbent's choice of $\varphi(2)$. Instead, we examine the impact of exogenously varying it for observable aspects of industry dynamics. The relative simplicity of our model allows us to characterize this experiment analytically. We complement these qualitative results with a numerical analysis of several model parameterizations.

\subsection{Qualitative Characterization of a Barrier's Impact}

Suppose that two firms serve the market in equilibrium with positive probability. Consider the graphical results from Figure 2. These clearly depend on the fact that entry and exit thresholds characterize the equilibrium strategy. This property seems both natural and intuitively desirable. However, it does not generally hold good. In Abbring and Campbell (2006), we calculate the equilibrium for an example in which, given two initial values $C_{L}<$ $C_{H}$, the distribution of $C_{t+1}$ given $C_{t}=C_{H}$ stochastically dominates the same distribution given $C_{t}=C_{L}$. Although this condition guarantees that thresholds give a monopolist's entry and exit decisions in a market that supports at most one firm, the equilibrium entry rule for a firm entering an empty industry that can hold two firms has no threshold representation. That is, there is a "hole" in the set of $C_{t}$ for which entry into an otherwise empty industry is rational. This difficulty obviously reflects the non-monotonic value function: Increasing $C_{t}$ can make future entry likely enough to reverse a firm's current entry decision. This difficulty does not manifest itself in the pencil-and-paper example, because there increasing $C_{t}$ has no impact on the likelihood of future entry.

In Abbring and Campbell (2006), we address this issue with a condition on the stochastic process for $C_{t}$ (weaker than that from the pencil-and-paper example) which guarantees a threshold representation for the equilibrium strategy. It ensures that increasing $C$ cannot 
move a "substantial" probability mass over another firm's entry threshold. Rather than repeat that analysis here, we make the following high-level assumption and refer the reader to the companion paper for a more primitive analysis.

Assumption 1. Given the stochastic process for $C_{t}$, all other model parameters, and any value of $\varphi(2) \geq \varphi(1)$, there exist four thresholds $\underline{C}_{1} \leq \bar{C}_{1}$ and $\underline{C}_{2} \leq \bar{C}_{2}$ such that $A_{E}(C, 1)=$ $I\left\{C>\bar{C}_{1}\right\}, A_{E}(C, 2)=I\left\{C>\bar{C}_{2}\right\}, A_{S}(0, C, 1)=A_{S}(1, C, 1)=I\left\{C>\underline{C}_{1}\right\}$, and $A_{S}(0, C, 2)=I\left\{C>\underline{C}_{2}\right\}$.

With this assumption in place, the graphical results from Figure 2 generalize immediately. ${ }^{3}$

Proposition 1. Increasing $\varphi(2)$ weakly increases $\bar{C}_{2}$, leaves $\underline{C}_{2}$ unchanged, and weakly decreases both $\bar{C}_{1}$ and $\underline{C}_{1}$.

The inequalities here and below are weak only because the threshold entry and exit rules can be trivial, prescribing activity or inactivity for all $C$.

Changes in the thresholds directly affect the evolution of the equilibrium number of firms. To see how, suppose that $\varphi(2)$ increases unexpectedly and permanently when the industry begins with a particular value of $C$ and no active producers. Entry of at least one firm occurs if and only if $C>\bar{C}_{1}$. So, increasing a contestant's entry cost increases the probability that some firm will service the industry immediately. Suppose instead that the industry begins with a single active incumbent. Because $\underline{C}_{1}$ decreases and $\bar{C}_{2}$ increases, any value of $C$ that induced neither entry nor exit will continue to do so. Hence, the probability of the industry remaining with exactly one firm increases. Finally, an industry that begins with two firms will remain unchanged in exactly the same conditions as before. The following proposition shows that this intuition extends to the probability for a change in the number of firms that conditions on the given initial values of $C$ and $N$.

Proposition 2. Let $S_{j}(C, N) \equiv \operatorname{Pr}\left\{N_{t+1}=\cdots=N_{t+j}=N \mid C_{t-1}=C, N_{t}=N\right\}$ denote the probability that the number of firms remains unchanged over $j$ periods given the initial numbers of consumers and firms. Then, raising $\varphi(2)$ weakly decreases $S_{j}(C, 0)$, weakly increases $S_{j}(C, 1)$, and leaves $S_{j}(C, 2)$ unchanged.

An immediate implication of Proposition 2 is that imposing a barrier to entry makes the structure of an active industry more stable in the short and medium run. We now turn to consider the effects of the entry barrier on that structure itself. The impact of $\varphi(2)$ on the

\footnotetext{
${ }^{3}$ Appendix A contains the proofs of this section's propositions.
} 
equilibrium entry and exit thresholds strongly suggests that the probabilities of having 0 or 2 firms declines with $\varphi(2)$. This is indeed the case

Proposition 3. Let $P_{j}\left(N^{\prime}, C, N\right) \equiv \operatorname{Pr}\left\{N_{t+j}=N^{\prime} \mid C_{t-1}=C, N_{t}=N\right\}$. Then raising $\varphi(2)$ weakly lowers $P_{j}(0, C, N)$ and $P_{j}(2, C, N)$.

This proposition's content is straightforward: Imposing a barrier to a contestant's entry increases the probability that the industry is serviced at the expense of decreasing the probability of a "competitive" industry structure. The literature on entry barriers does not ordinarily associate them with increasing the number of firms, but this effect is familiar from the analysis of patents: Increasing the cost of a imitator's entry encourages entry by an innovator. The model of this paper differs from one with patents in one substantial respect: The sunk cost of entry is weakly higher for a second entrant instead of lower. Nevertheless, this difference does not change the qualitative effects of a barrier to entry on the incentive for "innovation" (broadly construed).

Proposition 3 characterizes the number of firms at any given date in the future. In this sense, it characterizes the short- and medium-run responses to creating a barrier to entry. The following corollary extends its conclusions to the industry's ergodic distribution, if it exists.

Corollary 1. Suppose that $\left(C_{t-1}, N_{t}\right)$ has a unique ergodic distribution and let $P(N)$ denote the probability of $N$ firms serving the industry in this distribution. Then raising $\varphi(2)$ weakly decreases $P(0)$ and $P(2)$.

The omitted proof is an simple application of the bounded convergence theorem. By definition, the distribution of industry outcomes converges to the ergodic distribution as the time horizon grows large. However, this long run differs substantially from the two-stage analysis of industry structure which goes by the same label; because it gives a distribution of industry outcomes given ongoing uncertainty and sunk costs rather than a single outcome at the end of time.

We conclude this analytic characterization of the model's dynamics by considering the most familiar observable indicators of an industry's propensity to change its structure, its entry and exit rates. We define the net growth rate of the number of firms in the industry with $G_{t} \equiv 2 \times\left(N_{t}-N_{t-1}\right) /\left(N_{t}+N_{t-1}\right)$. With this, the industry's entry and exit rates are $E R_{t} \equiv \min \left\{0, G_{t}\right\}$ and $X R_{t} \equiv \min \left\{0,-G_{t}\right\}$. Because these are only well defined if either $N_{t}$ or $N_{t-1}$ is positive, we assume that $P(0)=0$. With this, the following proposition shows that raising $\varphi(2)$ has the expected effect of reducing average entry and exit rates. 
Proposition 4. Suppose that $\left(C_{t-1}, N_{t}\right)$ has a unique ergodic distribution with $P(0)=0$. Then increasing $\varphi(2)$ weakly decreases $\mathbb{E}\left[E R_{t}\right]=\mathbb{E}\left[X R_{t}\right]$, where the expectations are calculated using the ergodic distribution for $\left(C_{t-1}, N_{t}\right)$.

The proof relies on the fact that raising $\bar{C}_{2}$ reduces $P(2)$ and thereby all future dates' exit rates.

This completes the analytic characterization of the equilibrium impact of erecting barriers to a duopolist's entry. Analytic results from an infinite-horizon Markov-perfect equilibrium come infrequently, so their mere existence is somewhat novel. Nevertheless, Judd (1997) cautions against focusing only on surprising qualitative results without examining their quantitative importance. For this, we turn to a numerical exploration.

\subsection{Quantitative Assessment of a Barrier's Impact}

Calculation of the effects of barriers to entry requires us to assign values to the model's parameters. Estimating or calibrating them necessitates a much richer exploration of a particular industry's institutional background and technological constraints than is appropriate for this paper. Instead, we follow the strategy advocated by Judd (1997) and calculate the model's equilibrium dynamics at a wide range of parameter choices. This reveals which features of the model amplify or mute the above qualitative results.

\subsubsection{Model Specification}

Calculation of the model's equilibrium uses values for $\beta, \kappa, \pi(1), \pi(2), \varphi(1), \varphi(2)$, and the parameters of the stochastic process governing $C$. We suppose that a model period corresponds to five years and that the real interest rate is $5 \%$, so we set $\beta=1.05^{-5}$ for all of the model's parameterizations. We set the support of $\ln C$ to a grid of 301 evenly spaced points on $[-1.5,1.5]$ and we choose the stochastic process to approximate the linear autoregression $\ln C^{\prime}=\rho \ln C+u$, where $u$ has a normal distribution with mean zero and variance $\sigma^{2}$. The approximation is a mixture over 51 conditional distributions for $\ln C^{\prime}$ with a uniform distribution with support width $\sigma_{k}$ and and conditional mean

$$
\mu_{k}(C)= \begin{cases}\ln \hat{C}+\sigma_{k} / 2 & \text { if } \rho \ln C<\ln \hat{C}+\sigma_{k} / 2 \\ \rho \ln C & \text { if } \ln \hat{C}+\sigma_{k} / 2 \leq \rho \ln C \leq \ln \check{C}-\sigma_{k} / 2 \\ \ln \check{C}-\sigma_{k} / 2 & \text { if } \rho \ln C>\ln \check{C}-\sigma_{k} / 2\end{cases}
$$




\begin{tabular}{ll} 
Parameter & Possible Values \\
\hline$\beta$ & $1.05^{-5}$ \\
$\rho$ & $0.80,0.90,1.00$ \\
$\sigma$ & $0.10,0.20,0.30$ \\
$\kappa$ & 1 \\
$\varphi$ & $0,2 / 5,4 / 5$ \\
$\pi$ & 2
\end{tabular}

Table 1: Baseline Parameter Values for Numerical Experiments

This paper's replication file contains the details of their specification. Our calculations use three different values of $\rho-0.80,0.90$, and $1.0-$ and three values of $\sigma-0.10,0.20$, and 0.30. Only the specification with $\rho=1$ satisfies Abbring and Campbell's (2006) condition for threshold equilibrium entry and exit strategies, so our computational procedure does not require firms to employ such threshold rules.

We normalize the per-period fixed cost $\kappa$ to one. To begin, we suppose that the sunk costs of entry in an market that is not yet served and in a monopolistic market are the same, so that $\varphi(1)=\varphi(2)=\varphi$. We set $\varphi$ to either $0,2 / 5$, or $4 / 5 .{ }^{4}$ Because our model period is five years, these sunk costs correspond to 0,2 and 4 years of fixed costs, respectively. Conversely, their five-year rental equivalent values $\varphi(1-\beta) / \beta$ are $0,0.11$, and 0.22 .

Throughout, we assume that entry by a second producer has no effect on the producer's surplus per consumer served, $\pi(1)=\pi(2)=\pi$. This arises, for example, if producers are monopolistic price setters serving equal market shares. Sutton (1991) refers to the slope of $\pi(\cdot)$ as the "toughness" of competition. In this terminology, our specification exhibits low toughness of competition. ${ }^{5}$ We set $\pi=2$, so that the duopoly producer's surplus when $C=1$ equals $\kappa$. For reference, Table 1 reports all of the possible values we give to the model's parameters in the baseline experiments without barriers to entry.

\footnotetext{
${ }^{4}$ The case with $\varphi(N)=0$ is not equivalent to the infinite repetition of the static free-entry game, because a firm's operation in an earlier period gives it "priority" for serving the industry later.

${ }^{5}$ We have experimented with an alternative specification in which duopolists compete in quantities. This example of Cournot duopoly gives $\pi(2)=\pi(1) / 2$ and thus exhibits high toughness of competition relative to our baseline specification. We do not report numerical results for this specification, because they are very close to the results for our baseline specification, given appropriate normalizations of the level of demand.
} 

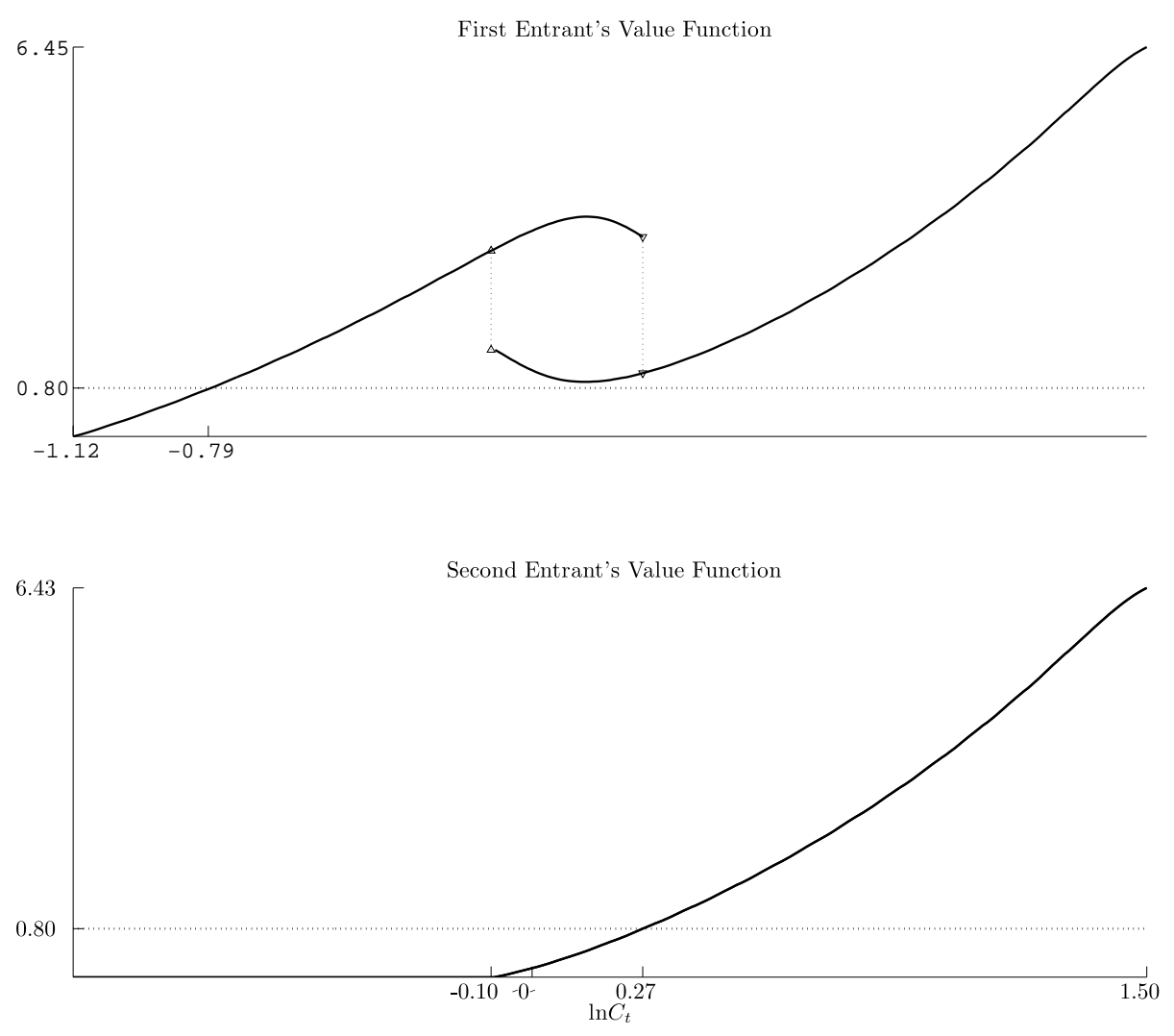

Figure 3: Firms' Value Functions in the Leading Example

\subsubsection{A Specific Example}

It is helpful to have a specific example in mind when considering the results of all of the experiments. For this, we set $\rho=0.9, \sigma=0.2, \varphi=4 / 5$, and $\pi=2$. Figure 3 plots the value functions of the two firms that might serve this industry. Its bottom panel displays the value of a firm that has entered as a duopolist. This weakly increases with demand. The value of continuation exceeds the cost of entry if $\ln C_{t}>0.27$, and it equals zero if $\ln C_{t} \leq-0.10$.

Figure 3's top panel plots the value of a firm that has entered as a monopolist. This has the same structure as the plot of the incumbent's value function in Figure 2. The upper branch corresponds to the value function when the industry has one firm, and the lower branch gives the first firm's value after the entry of a second firm. The arrows indicate that 
the first firm's value drops when the second firm enters and jumps after its exit. Unlike in Figure 2, the monopoly and duopoly branches decrease near the second entrant's entry and exit threshold, respectively. This reflects the fact that here, unlike in the pencil-and-paper example, a higher realization of $C_{t}$ corresponds to a higher probability that a second firm is active in the future. The stochastic process for $\ln C_{t}$ does not satisfy Abbring and Campbell's (2006) sufficient condition for threshold equilibrium entry and exit strategies. Nevertheless, entry and exit thresholds, equal to -0.79 and -1.12 , characterize this firm's decisions.

To measure the impact of barriers to entry on equilibrium dynamics, we concentrate on the number of firms' average and standard deviation in the equilibrium's ergodic distribution. In this example, the average number of firms is 1.32 and the standard deviation is 0.47 . The barrier to entry we examine adds $4 / 5$ to the sunk cost of a second firm's entry. With this modification, the second entrant's entry threshold rises from 0.27 to 0.52 . As Section 3.1's results suggest, increasing the second entrant's sunk costs encourages a first entrant. However, even though the increase in these costs amount to a substantial four years of fixed cost; the first entrant's entry and exit thresholds drop very little. By construction, the second entrant's exit threshold remains unchanged. As a result of all this, the average and standard deviation for the number of firms drop to 1.08 and 0.28 . Thus, the intuition that raising a barrier to entry stabilizes the number of firms holds good. Furthermore, the decrease in the average number of firms conforms to the intuition from two-stage models that barriers to entry increase concentration. In this particular example, imposing a barrier to entry hardly changes the decision to enter or abandon an otherwise empty industry.

\subsubsection{Experimental Results}

Table 2 reports the average and standard deviation for $N_{t}$ from the ergodic distribution for all combinations of the parameter values we consider. The cost of entry influences the average number of firms as expected. In all of the comparisons across parameterizations, raising $\varphi$ lowers the average number of firms. However, it lowers the number of firms much more if $\rho$ is low. For example, when $\sigma=0.1$, raising $\varphi$ from 0 to $4 / 5$ decreases the number of firms from 1.66 to 1.00 if $\rho=0.8$. When $\rho=1.0$, the same change lowers the average from 1.27 to 1.19 .

A second notable pattern is that raising $\sigma$ always increases the average number of firms. This arises from the well-known effect of uncertainty on the real option embedded in a firm's value explained by Dixit and Pindyck (1994). Because firms can exit following an unprofitable realization of $C_{t}$, uncertainty increases a firm's value and in this way promotes entry. 


\begin{tabular}{cc|ccc|ccc} 
& & \multicolumn{3}{|c|}{ Average } & \multicolumn{3}{c}{ Standard Deviation } \\
$\rho$ & $\sigma$ & $\varphi=0.0$ & $\varphi=0.4$ & $\varphi=0.8$ & $\varphi=0.0$ & $\varphi=0.4$ & $\varphi=0.8$ \\
\hline 0.80 & 0.10 & 1.66 & 1.04 & 1.00 & 0.47 & 0.19 & 0.00 \\
0.90 & 0.10 & 1.65 & 1.30 & 1.04 & 0.48 & 0.46 & 0.21 \\
1.00 & 0.10 & 1.27 & 1.22 & 1.19 & 0.83 & 0.84 & 0.85 \\
0.80 & 0.20 & 1.70 & 1.35 & 1.07 & 0.46 & 0.48 & 0.26 \\
0.90 & 0.20 & 1.66 & 1.48 & 1.32 & 0.47 & 0.50 & 0.47 \\
1.00 & 0.20 & 1.33 & 1.27 & 1.23 & 0.80 & 0.82 & 0.83 \\
0.80 & 0.30 & 1.72 & 1.50 & 1.28 & 0.45 & 0.50 & 0.45 \\
0.90 & 0.30 & 1.66 & 1.54 & 1.44 & 0.47 & 0.50 & 0.50 \\
1.00 & 0.30 & 1.39 & 1.32 & 1.28 & 0.77 & 0.80 & 0.81
\end{tabular}

Table 2: The Number of Firms in the Ergodic Distribution

The most notable feature of Table 2's second panel is the relatively small impact of raising $\varphi$ on the standard deviation of $N_{t}$, unless both $\rho$ and $\sigma$ are small. In the four cases with the lowest standard deviations, the industry is almost certainly a monopoly. ${ }^{6}$ The probability of two firms serving the industry with all of the other specifications are substantial, but the industry is likely to be inactive only if $\rho=1$. These cases with substantial probabilities on all three possible outcomes have the highest standard deviations.

Table 3 reports the changes in the number of firms' average and standard deviation from raising a barrier to entry. For each parameter combination, the cost of a second firm's entry was increased by $4 / 5$ as in the leading example. In the reported experiments, raising a barrier either lowers the average number of firms or leaves it unchanged. The largest decrease is 0.66 firms. In this case, the barrier completely deters a potential entrant. In the four cases in which the market is unlikely to hold two active firms initially, raising $\varphi(2)$ hardly changes the average number of firms. A clear pattern emerges after eliminating these cases: Raising a barrier to entry substantially lowers the average number of firms unless $\rho=1$. With highly persistent demand shocks, the average number of firms falls only trivially. The barrier's effect on the standard deviation also depends on the persistence of demand. Except in two cases, the barrier decreases the standard deviation. This is the stabilization of market structure that Proposition 3 leads us to expect. However, the standard deviation's decline is always trivial in the cases with $\rho=1$.

To determine why the barrier to entry has such small effects with persistent demand

\footnotetext{
${ }^{6}$ These cases are $(\varphi, \rho, \sigma)=(2 / 5,0.80,0.10),(4 / 5,0.80,0.10),(4 / 5,0.90,0.10)$, and $(4 / 5,0.80,0.20)$.
} 


\begin{tabular}{cc|ccc|ccc} 
& & \multicolumn{3}{|c|}{ Average } & \multicolumn{3}{c}{ Standard Deviation } \\
$\rho$ & $\sigma$ & $\varphi=0.0$ & $\varphi=0.4$ & $\varphi=0.8$ & $\varphi=0.0$ & $\varphi=0.4$ & $\varphi=0.8$ \\
\hline 0.80 & 0.10 & -0.66 & -0.04 & 0.00 & -0.47 & -0.19 & 0.00 \\
0.90 & 0.10 & -0.61 & -0.30 & -0.04 & -0.27 & -0.42 & -0.20 \\
1.00 & 0.10 & -0.04 & -0.03 & -0.03 & -0.01 & -0.01 & -0.01 \\
0.80 & 0.20 & -0.62 & -0.35 & -0.07 & -0.20 & -0.42 & -0.25 \\
0.90 & 0.20 & -0.34 & -0.30 & -0.23 & -0.01 & -0.11 & -0.19 \\
1.00 & 0.20 & -0.05 & -0.04 & -0.03 & -0.02 & -0.01 & -0.01 \\
0.80 & 0.30 & -0.44 & -0.39 & -0.26 & 0.00 & -0.19 & -0.30 \\
0.90 & 0.30 & -0.22 & -0.20 & -0.18 & 0.02 & -0.02 & -0.06 \\
1.00 & 0.30 & -0.05 & -0.04 & -0.03 & -0.02 & -0.02 & -0.02
\end{tabular}

Table 3: Effects of Imposing a Barrier to Entry on the Number of Firms

shocks, we began with an inspection of the (unreported) changes in the ergodic distributions and thresholds underlying Table 3's results. We found that the barrier had a negligible entryencouraging effect with all parameterizations. It changes neither the first entrant's thresholds nor the probability of an inactive market substantially. The barrier's direct deterrent effects explain the decreases in the average number of firms. The absence of a substantial effect in the cases with $\rho=1$ corresponds to small deterrent effects, not to offsetting entry-encouraging effects. Even though the youngest firm's entry threshold increases, the resulting change in the probability of an active duopoly is small in these cases. Consequently, the changes in the number of firms' standard deviations are also small. ${ }^{7}$

The case with very persistent demand shocks obviously has empirical relevance, so it is worth confirming that the very small effect of a barrier to entry we document is not specific to the particular parameterizations used to create Table 3. To show this, we recalculated the results of the same experiment for a variety of alternative parameter values. Increasing the barrier from $4 / 5$ to $8 / 5$ leads to somewhat more pronounced effects without changing the

\footnotetext{
${ }^{7}$ The pencil-and-paper example provides a qualitative understanding of how the effects of a barrier to entry depend on the persistence of demand. There, the ergodic distribution of $\left(C_{t-1}, N_{t}\right)$ only depends on the persistence parameter $\lambda$ through the thresholds. If we increase persistence by decreasing $\lambda$, then the slope of the younger duopolist's value function directly increases. This makes $\bar{C}_{2}$ less sensitive to changes in the sunk cost of entry. In the general model, the persistence parameter $\rho$ affects the ergodic distribution not only indirectly through the thresholds, but also directly. The numerical experiments confirm the pencil-and-paper example's intuition that the thresholds are less sensitive to a barrier to entry if $\rho=1$. They also show that the direct effect of $\rho$ explains some of the fall in sensitivity to a barrier to entry.
} 
main conclusions. The results for the cases with $\rho=1$ also continue to hold for larger values of $\sigma$ than those reported in Table 3. In the case with $\varphi=0$ and $\sigma$ as high as 0.60 , raising a barrier to entry entices a first entrant to lower its entry and exit thresholds so that it becomes and remains active at all demand levels. Consequently, the market is somewhat more likely to be served by at least one firm, and the average number of firms increases slightly (by 0.02) in this case. This shows that the entry-encouraging effect exists and can lead to an increase in the number of firms without changing our conclusion that it is numerically unimportant. Finally, we experimented with many alternative specifications of $\pi(1)$ and $\pi(2)$ to ensure that our results did not depend on assuming that competition is not tough. In specifications with $\pi(2)<\pi(1)$ and $\rho=1$, a barrier to entry continues to affect industry dynamics only trivially.

\section{A First-In First-Out Example}

The above analysis heavily leverages the LIFO assumption. Although we find this assumption natural for the reasons given above, confirmation that our results can be obtained without it enhances confidence in their conclusions. Here, we present one such case which uses the stochastic process for $C$ from the paper-and-pencil example. We replace the assumption that older firms make their continuation decisions first with its opposite, and we focus on equilibria in which older firms exit before their younger competitors. We refer to this as the first-in first-out (FIFO) example. As in the original model, de novo entry decisions follow incumbents' continuation decisions. We limit entry into the industry to at most one firm per period. ${ }^{8}$

In Appendix B, we show that an equilibrium in a FIFO strategy that is characterized by threshold rules exists, provided that $\varphi(1)$ is sufficiently small and $\varphi(2)$ is sufficiently large. ${ }^{9}$ Figure 4 plots this equilibrium's value functions for a case in which $\varphi(2)=\varphi(1) .{ }^{10}$ The solid black line represents the value of a firm with rank 1. As before, it has monopoly and duopoly

\footnotetext{
${ }^{8}$ This final assumption avoids complications that arise when there are no incumbents, the value of being a duopolist with rank 2 exceeds $\varphi(2)$, and the value of being a duopolist with rank 1 is less than $\varphi(1)$.

${ }^{9}$ Unlike in the LIFO case, we do not demonstrate that there is a unique Markov-perfect equilibrium in a FIFO strategy. The equilibrium constructed in Appendix B is merely the unique equilibrium in which a threshold rule governs a contestant's entry.

${ }^{10}$ To create Figure 4, and Figure 5 in Appendix B, we calculated the equilibrium for particular parameter values so that the bounds on $\varphi(1)$ and $\varphi(2)$ are satisfied (Assumptions 2 and 3 in Appendix B), so the analysis in Appendix B does not presume an impossible configuration of parameters.
} 


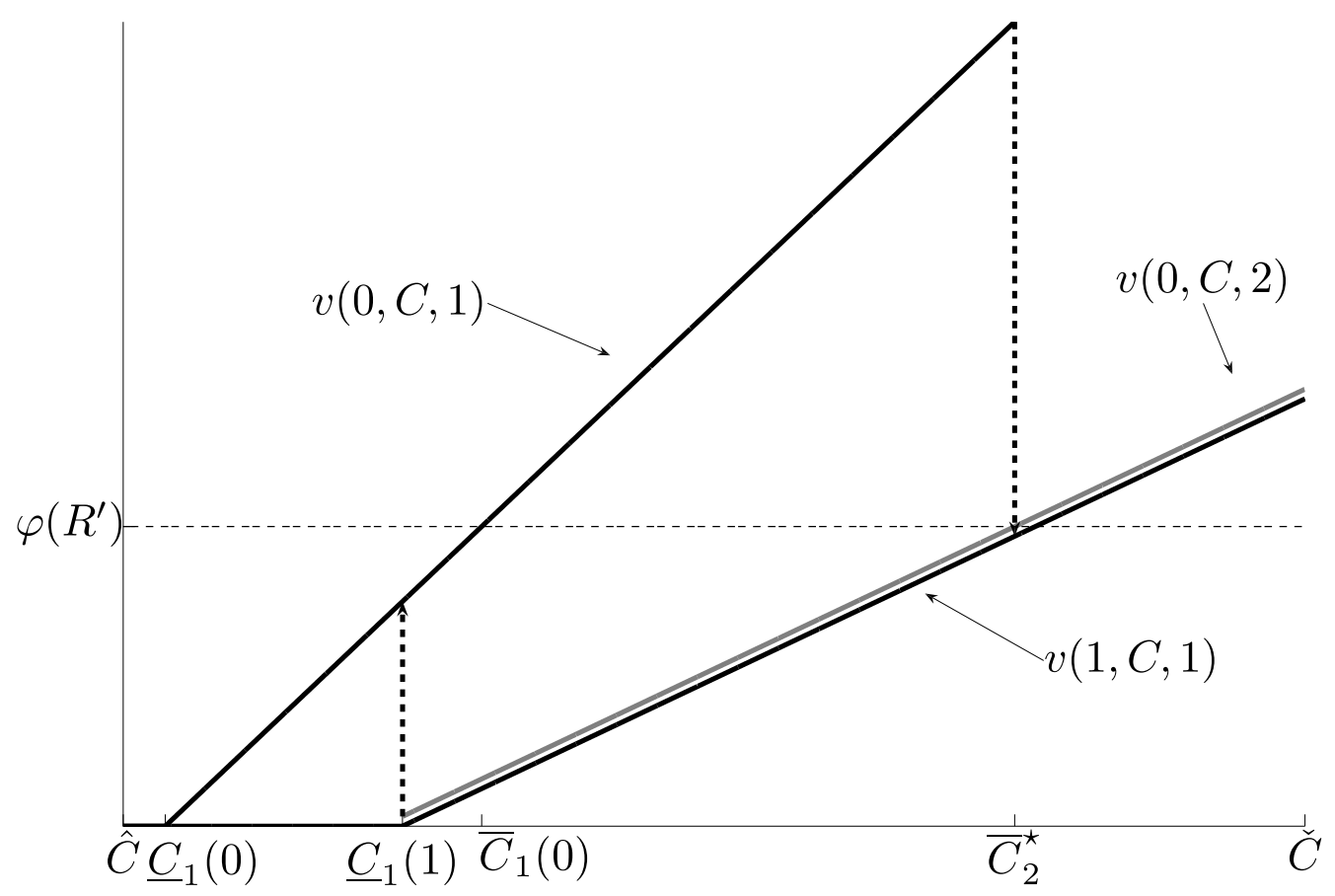

Figure 4: Equilibrium in the FIFO Example

branches. They intersect the horizontal axis at $\underline{C}_{1}(0)$ and $\underline{C}_{1}(1)$. The grey line gives the value of a firm with rank 2 . This is slightly above the rank 1 duopoly branch and far below the rank 1 monopoly branch. Suppose that initially $N=2$. If $C$ passes below $\underline{C}_{1}(1)$, then the older firm exits and the younger firm's value jumps to the rank 1 monopoly branch. ${ }^{11}$ If $C$ then jumps above $\bar{C}_{2}^{\star}$, another firm enters and the original firm's value falls to the rank 1 duopoly branch.

Now consider the consequences of raising $\varphi(2)$ while holding $\varphi(1)$ constant. In Appendix $\mathrm{B}$, we prove

Proposition 5. Increasing $\varphi(2)$ alone weakly increases $\bar{C}_{2}^{\star}$, weakly decreases $\underline{C}_{1}(0)$ and $\bar{C}_{1}(0)$, and leaves $\underline{C}_{1}(1)$ unchanged.

This proposition is nearly identical to its predecessor from the general analysis of duopoly

\footnotetext{
${ }^{11}$ The discount rate used to calculate this example was relatively high, so this possibility contributes little to the value of a duopolist with rank 1.
} 
with a symmetric LIFO strategy. There, $\underline{C}_{1}$ and $\bar{C}_{1}$ play the same role as $\underline{C}_{1}(0)$ and $\bar{C}_{1}(0)$ here, while the FIFO analogue of $\underline{C}_{2}$ is $\underline{C}_{1}(1)$. Extending the propositions from the LIFO duopoly to this FIFO case thus requires only relabeling the relevant thresholds. For the sake of completeness, we state them here. ${ }^{12}$

Proposition 6. Define $S_{j}(C, N)$ as in Proposition 2. Raising $\varphi(2)$ weakly decreases $S_{j}(C, 0)$, weakly increases $S_{j}(C, 1)$, and leaves $S_{j}(C, 2)$ unchanged.

Proposition 7. Define $P_{j}\left(N^{\prime}, C, N\right)$ as in Proposition 3. Raising $\varphi(2)$ weakly decreases $P_{j}(0, C, N)$ and $P_{j}(2, C, N)$.

Corollary 2. Denote the probability of $N$ firms serving the industry in the ergodic distribution for $(C, N)$ with $P(N)$. Raising $\varphi(2)$ weakly decreases $P(0)$ and $P(2)$ and increases $P(1)$.

Proposition 8. Suppose that $\left(C_{t-1}, N_{t}\right)$ has a unique ergodic distribution with $P(0)=0$. Then increasing $\varphi(2)$ weakly decreases both $\mathbb{E}\left[E R_{t}\right]$ and $\mathbb{E}\left[X R_{t}\right]$, where the expectations are calculated using the ergodic distribution for $\left(C_{t-1}, N_{t}\right)$.

It is somewhat remarkable that the same results hold good for the opposite extreme assumptions of LIFO and FIFO entry and exit for this particular stochastic process. This reflects the robustness of two economic principles from finite-stage games. First, raising the cost of late entry directly deters that entry. Second, this deterrence indirectly encourages early entry. Of course, there are specifications for the dynamic game of entry and exit other than LIFO and FIFO, so showing that the analytic duopoly results are robust to this change does not demonstrate that they always hold good. Nevertheless, it does show that a LIFO pattern for entry and exit is not necessary for this paper's analytic results.

\section{$5 \quad$ Related Literature}

This paper implicitly relies upon a great deal of previous work. This section serves to acknowledge this dependence explicitly. There are three areas of previous research that are particularly important for us.

\footnotetext{
${ }^{12}$ The corollary and final proposition take for granted the fact that $(C, N)$ does have an ergodic distribution.
} 


\subsection{Entry Deterrence}

Barriers to entry play a prominent role in the structure-conduct-performance framework, because no firm can maintain market power without an impediment to competition. Subsequent work using game-theoretic tools examined incumbents' ability to deter entry. Dixit (1980) pioneered this with a demonstration that an incumbent's investment can deter entry by committing the firm to tough post-entry price competition, and Milgrom and Roberts (1982) continued this by showing how actions with no intrinsic dynamic consequences can nevertheless deter entry by credibly signalling the incumbent's payoff-relevant private information. Much work has followed this delineating the tools available to incumbents for entry deterrence. Unlike that work, we take as given the existence of an economic entry barrier (defined as in McAfee, Mialon, and Williams, 2004); and we focus instead on such a barrier's dynamic consequences.

\subsection{Competitive Industry Dynamics}

We are not the first to analyze the influence of sunk costs on industry structure in an infinitehorizon framework. Hopenhayn (1992) does so in a model of competitive industry dynamics with atomistic price taking firms. He shows that increasing the sunk cost of entry lowers entry and exit rates in his model's stationary equilibrium. This result is reminiscent of our Proposition 4, but the two results reflect entirely different mechanisms. In our model, raising a second entrant's sunk cost raises that firm's entry threshold and leaves the exit threshold unchanged. The reduction in entry and exit rates arises from the greater distance that $C_{t}$ must fall before inducing that firm to exit. In Hopenhayn's model, raising the sunk cost of entry directly raises the competitive equilibrium price, which in turn lowers firms' common exit threshold.

Models of industry dynamics that assume either perfect competition (such as Jovanovic's, 1982 or Hopenhayn's, 1992) or monopolistic competition without strategic interaction (such as Fishman and Rob's, 2003) have proven invaluable in the empirical analysis of firm and industry evolution, because they replicate the large simultaneous entry and exit rates documented by Dunne, Roberts, and Samuelson (1988). These models abstract from strategic interaction, so they are very tractable. However, they imply nothing for the evolution of oligopolistic markets. Campbell and Hopenhayn (2005) and Campbell (2006) have documented that observations from U.S. cities' retail trade industries generally conflict with these non-strategic models' cross-market predictions, so their further analysis apparently requires 
consideration of oligopoly. The appropriate extension of this paper's model can serve as the foundation of such work if we consider a given industry with many firms to be a collection of many oligopolies.

\subsection{Computational Analysis of Competition Policy}

Our focus on the positive consequences of erecting a barrier to entry places our work close to previous investigations of competition policy in dynamic settings. For example, Fershtman and Pakes (2000) examine the effects of collusive pricing on the number and quality of products offered by an oligopoly; and Cheong and Judd (2000) examine mergers' profitability and welfare consequences in an infinite-horizon setting with aspects of both Bertrand and Cournot competition. Those papers' results come from computed Markov-perfect equilibria. This paper's model considers only two forward-looking decisions (entry and exit); and this simplicity allows us to obtain some of our results analytically. Judd (1997) opines that analytical results from special cases of otherwise intractable dynamic models complement computational results from richer parameterizations. This paper's use of analytical and numerical results to reinforce each other embodies this complementarity.

\section{Conclusion}

The phrase "barriers to entry" has a long history in industrial organization, much of which revolves around its imprecise definition. We adopt a specific definition - sunk costs that only late entrants pay - and examine their effects on duopoly dynamics in a particular Markov-perfect equilibrium. In theory, exogenously imposing a barrier to entry can either raise or lower the number of competitors, but we show that the barrier's entry-encouraging effects are quantitatively unimportant. If demand is not very persistent, then the barrier's direct deterrent effects are substantial. However, a barrier to entry effects the number of competitors little in the empirically-relevant case with highly persistent demand shocks.

The numerical procedure that we have used to calculate the effects of barriers to entry in a potential duopoly can be applied directly to industries that support more than two firms. For an example of this, see Abbring and Campbell (2006). An extension of this paper's analysis to general oligopolies presents nontrivial economic difficulties, because it involves several incumbents jointly erecting barriers to deter multiple contestants' entry. Sorting this out by modelling the actions that create barriers to entry lies beyond the scope of this paper. 


\section{References}

Abbring, J. H. and J. R. Campbell (2006). Last-in first-out oligopoly dynamics. Federal Reserve Bank of Chicago Working Paper 2006-28. 1, 3, 4, 5, 9, 13, 15, 22

Cabral, L. M. (1993). Experience advantages and entry dynamics. Journal of Economic Theory 59, 403-416. 2

Campbell, J. R. (2006). Competition in large markets. Federal Reserve Bank of Chicago Working Paper 2005-16. 21

Campbell, J. R. and H. A. Hopenhayn (2005). Market size matters. Journal of Industrial Economics 53(1), 1-25. 21

Carlton, D. W. (2004). Why barriers to entry are barriers to understanding. American Economic Review 94(2), 466-470. 0, 2

Cheong, K.-S. and K. L. Judd (2000). Mergers and dynamic oligopoly. Journal of Economic Dynamics and Control Forthcoming. 22

Dixit, A. K. (1980, March). The role of investment in entry-deterrence. Economic Journal $90(357), 95-106.21$

Dixit, A. K. and R. S. Pindyck (1994). Investment under Uncertainty. Princeton University Press. 15

Dunne, T., M. J. Roberts, and L. Samuelson (1988). Patterns of firm entry and exit in U.S. manufacturing industries. Rand Journal of Economics 19, 495-515. 21

Fershtman, C. and A. Pakes (2000). A dynamic oligopoly with collusion and price wars. Rand Journal of Economics 31(2), 207-236. 22

Fishman, A. and R. Rob (2003). Consumer inertia, firm growth and industry dynamics. Journal of Economic Theory 109(1), 24-38. 21

Hopenhayn, H. A. (1992). Entry, exit, and firm dynamics in long run equilibrium. Econometrica 60(5), 1127-1150. 21

Jovanovic, B. (1982). Selection and the evolution of industry. Econometrica 50(3), 649-670. 21 
Judd, K. L. (1997). Computational economics and economic theory: Substitutes or complements? Journal of Economic Dynamics and Control 21, 907-942. 12, 22

McAfee, R. P., H. M. Mialon, and M. A. Williams (2004). What is a barrier to entry? American Economic Review 94 (2), 461-465. 2, 21

Milgrom, P. and J. Roberts (1982). Limit pricing and entry under incomplete information: An equilibrium analysis. Econometrica 50(2), 443-460. 21

Sutton, J. (1991). Sunk Costs and Market Structure. Cambridge, MA: MIT Press. 13 


\section{Appendix A Proofs of Results in Section 3}

Proof of Proposition 2. We begin with $S_{j}(C, 0)$. This equals $\operatorname{Pr}\left[\bigcap_{i=0}^{j-1}\left\{C_{t+i} \leq \bar{C}_{1}\right\} \mid C_{t-1}=C\right]$, which is clearly increasing in $\bar{C}_{1}$. Next, note that $S_{j}(C, 2)=\operatorname{Pr}\left[\bigcap_{i=0}^{j-1}\left\{C_{t+i}>\underline{C}_{2}\right\} \mid C_{t-1}=C\right]$, which is decreasing in $\underline{C}_{2}$. Finally, $S_{j}(C, 1)=\operatorname{Pr}\left[\bigcap_{i=0}^{j-1}\left\{\underline{C}_{1}<C_{t+i} \leq \bar{C}_{2}\right\} \mid C_{t-1}=C\right]$, which decreases with $\underline{C}_{1}$ and increases with $\bar{C}_{2}$. The conclusion follows immediately from Proposition 1.

Proof of Proposition 3. First, consider $P_{j}(0, C, N)$. Given $N_{t}=N>0$, the event $N_{t+j}=0$ equals

$$
A_{0}(j-1) \equiv \bigcup_{i=0}^{j-2}\left\{\left\{C_{t+i} \leq \underline{C}_{1}\right\} \bigcap_{k=i+1}^{j-1}\left\{C_{t+k} \leq \bar{C}_{1}\right\}\right\} \bigcup\left\{C_{t+j-1} \leq \underline{C}_{1}\right\}
$$

That is, the state must pass below $\underline{C}_{1}$ at some date $t+i$ and thereafter remain below $\bar{C}_{1}$ until $t+j$. Given $N_{t}=N=0$, the event $N_{t+j}=0$ equals $A_{0}(t, j-1) \cup B_{0}(t, j-1)$, where

$$
B_{0}(t, j-1) \equiv \bigcap_{i=0}^{j-1}\left\{C_{t+j} \leq \bar{C}_{1}\right\}
$$

Similarly, given $N_{t}=N<2$, the event $N_{t+j}=2$ equals

$$
A_{2}(t, j-1) \equiv \bigcup_{i=0}^{j-2}\left\{\left\{C_{t+i} \geq \bar{C}_{2}\right\} \bigcap_{k=i+1}^{j-1}\left\{C_{t+k} \geq \underline{C}_{2}\right\}\right\} \bigcup\left\{C_{t+j-1} \geq \bar{C}_{2}\right\}
$$

and given $N_{t}=N=2$, this event equals $A_{2}(t, j-1) \cup B_{2}(t, j-1)$, where

$$
B_{2}(t, j-1) \equiv \bigcap_{i=0}^{j-1}\left\{C_{t+j} \geq \underline{C}_{2}\right\}
$$

The sets $A_{0}(t, j-1)$ and $B_{0}(t, j-1)$ are both increasing in $\underline{C}_{1}$ and $\bar{C}_{1}$, and both $A_{2}(t, j-1)$ and $B_{2}(t, j-1)$ are decreasing in $\underline{C}_{2}$ and $\bar{C}_{2}$. The conclusion that $P_{j}(0, C, N)$ and $P_{j}(2, C, N)$ decrease as $\varphi(2)$ increases follows immediately from this and Proposition 1.

Proof of Proposition 4. Without loss of generality, take as given that $\left(C_{0}, N_{1}\right)=(C, 1)$. Then $X R_{t}=2 / 3$ if the event $A_{2}(1, t-2) \bigcap\left\{C_{t} \leq \underline{C}_{2}\right\}$ occurs, and $X R_{t}=0$ otherwise. The set $A_{2}(1, t-2) \bigcap\left\{C_{t} \leq \underline{C}_{2}\right\}$ is decreasing in $\bar{C}_{2}$, so we have that $\mathbb{E}\left[X R_{t} \mid C_{0}=C, N_{1}=1\right]$ is decreasing in $\varphi(2)$. Taking the limit as $t \rightarrow \infty$ yields the result that the expected value of $X R_{t}$ calculated using the ergodic distribution decreases with $\varphi(2)$. The conclusion then follows from the fact that $\mathbb{E}\left[E R_{t}\right]=\mathbb{E}\left[X R_{t}\right]$ in the ergodic distribution. 


\section{Appendix B Section 4's First-In First-Out Example}

We continue to denote a firm's rank with $R$, but the FIFO assumption implies that a firm's rank can decrease during its lifetime. To begin, consider the continuation decision of an duopolist with rank 1 . This firm rationally expects its rival to not exit before it does, so the corresponding dynamic programming problem is identical to the problem of a duopolist with rank 2 under LIFO:

$$
v(1, C, 1)= \begin{cases}0 & \text { if } C \leq \underline{C}_{1}(1), \\ \beta \frac{(1-\lambda)\left(\frac{C}{2} \pi(2)-\kappa\right)+\lambda \widetilde{v}(1,1)}{1-\beta(1-\lambda)} & \text { if } C>\underline{C}_{1}(1) .\end{cases}
$$

Here, $\underline{C}_{1}(1)$ is the largest value of $C$ that sets $v(1, C, 1)$ to zero and

$$
\widetilde{v}(1,1)=\frac{1}{2}\left(\frac{\hat{C}+\check{C}}{2}\right) \pi(2)-\kappa+\int_{\hat{C}}^{\check{C}} \frac{v\left(1, C^{\prime}, 1\right)}{(\check{C}-\hat{C})} d C^{\prime} .
$$

This value function is identical to $v(0, C, 2)$ from the paper-and-pencil LIFO example.

The decisions of a potential or actual incumbent monopolist depend on their expectations for further entry. To calculate an equilibrium we suppose that all future potential duopolists actually enter if and only if $C>\bar{C}_{2}$. We then place conditions on the parameters that guarantee that the best response by a current potential duopolist to such a strategy is to enter if and only if $C$ exceeds a threshold $\bar{C}_{2}^{\prime}$. With this in place, we demonstrate that there is a unique value of this threshold that is its own best response. Finally, we characterize the entry decisions of a potential monopolist given this equilibrium duopoly entry policy.

Begin with a given value for $\bar{C}_{2}$. With this, we can specify the closely related dynamic programming problems of an incumbent monopolist and of an incumbent duopolist with rank 2. Their value functions satisfy

$$
v(0, C, 1)= \begin{cases}0 & \text { if } C \leq \underline{C}_{1}(0), \\ \beta \frac{(1-\lambda)(C \pi(1)-\kappa)+\lambda \tilde{v}(0,1)}{1-\beta(1-\lambda)} & \text { if } \underline{C}_{1}(0)<C \leq \bar{C}_{2}, \\ \beta \frac{(1-\lambda)\left(\frac{C}{2} \pi(2)-\kappa\right)+\lambda \tilde{v}(1,1)}{1-\beta(1-\lambda)} & \text { if } C>\bar{C}_{2},\end{cases}
$$

and

$$
v(0, C, 2)= \begin{cases}0 & \text { if } C \leq \underline{C}_{1}(0), \\ \beta \frac{(1-\lambda)(C \pi(1)-\kappa)+\lambda \tilde{v}(0,1)}{1-\beta(1-\lambda)} & \text { if } \underline{C}_{1}(0)<C \leq \underline{C}_{1}(1), \\ \beta \frac{(1-\lambda)\left(\frac{C}{2} \pi(2)-\kappa\right)+\lambda \widetilde{v}(0,2)}{1-\beta(1-\lambda)} & \text { if } C>\underline{C}_{1}(1) .\end{cases}
$$


As above,

$$
\widetilde{v}(0,1)=\left(\frac{\hat{C}+\check{C}}{2}\right) \pi(1)-\kappa+\int_{\hat{C}}^{\check{C}} \frac{v\left(0, C^{\prime}, 1\right)}{(\check{C}-\hat{C})} d C^{\prime}
$$

and

$$
\widetilde{v}(0,2)=\frac{1}{2}\left(\frac{\hat{C}+\check{C}}{2}\right) \pi(2)-\kappa+\int_{\hat{C}}^{\check{C}} \frac{v\left(0, C^{\prime}, 2\right)}{(\check{C}-\hat{C})} d C^{\prime} .
$$

The threshold $\underline{C}_{1}(1)$ is that defined from the older incumbent duopolist's problem, and the threshold $\underline{C}_{1}(0)$ is the greatest value of $C$ such that $v(0, C, 1)=0$.

We can now consider the entry decision of a potential duopolist given that all future potential duopolists use the threshold $\bar{C}_{2}$. We simplify the analysis with the assumption that such entry is never optimal if it immediately induces the incumbent to exit.

Assumption 2. If $\bar{C}_{2}=\check{C}$, then $v\left(0, \underline{C}_{1}(1), 2\right)<\varphi(2)$.

Because $\varphi(2)$ played no role in the construction of $v\left(0, \underline{C}_{1}(1), 2\right)$, Assumption 2 places a (possibly trivial) lower bound on $\varphi(2)$. With Assumption 2 in place, the incumbent chooses to continue and the potential entrant stays out of the market when $\underline{C}_{1}(0)<C<\underline{C}_{1}(1)$.

If $C>\underline{C}_{1}(1)$, continuation is a dominant strategy for the incumbent; and the branch of $v(0, C, 2)$ to the right of $\underline{C}_{1}(1)$ gives the payoff from entry. This is linear and increasing in $C$, and Assumption 2 implies that it is below $\varphi(2)$ for $C$ close to $\underline{C}_{1}(1)$. Define $\bar{C}_{2}^{\prime}\left(\bar{C}_{2}\right)$ to equal the greatest value of $C$ such that $v(0, C, 2) \leq \varphi(2)$. Creating a duopoly through entry is optimal if $C$ exceeds this threshold.

Figure 5 plots $\bar{C}_{2}^{\prime}\left(\bar{C}_{2}\right)$ for an example that satisfies Assumption 2. Increasing $\bar{C}_{2}$ increases the value of entering as a duopolist, so $\bar{C}_{2}^{\prime}(\cdot)$ is weakly decreasing. It is not difficult to demonstrate that it is also continuous, so it has a unique fixed point if $\bar{C}^{\prime}(\check{C})<\check{C}$. In this case, we set $\bar{C}_{2}^{\star}$ to that fixed point. If $\bar{C}^{\prime}(\check{C}) \geq \check{C}$, then we set $\bar{C}_{2}^{\star}$ to $\check{C}$. In either case, $\bar{C}_{2}^{\star}$ is the only possible equilibrium entry threshold for a second duopolist in an equilibrium with a FIFO strategy. ${ }^{13}$

Determining the threshold for entry into the industry when it has no incumbents completes the determination of equilibrium entry and exit rules. By assumption, a firm entering an empty industry will be a monopolist for one period. If $C \leq \bar{C}_{2}^{\star}$, the firm's payoff in the

\footnotetext{
${ }^{13}$ Unlike in the LIFO case, we have not demonstrated here that there is a unique Markov-perfect equilibrium in a FIFO strategy. The equilibrium under construction is merely the unique equilibrium in which a threshold rule governs a potential duopolist's entry.
} 


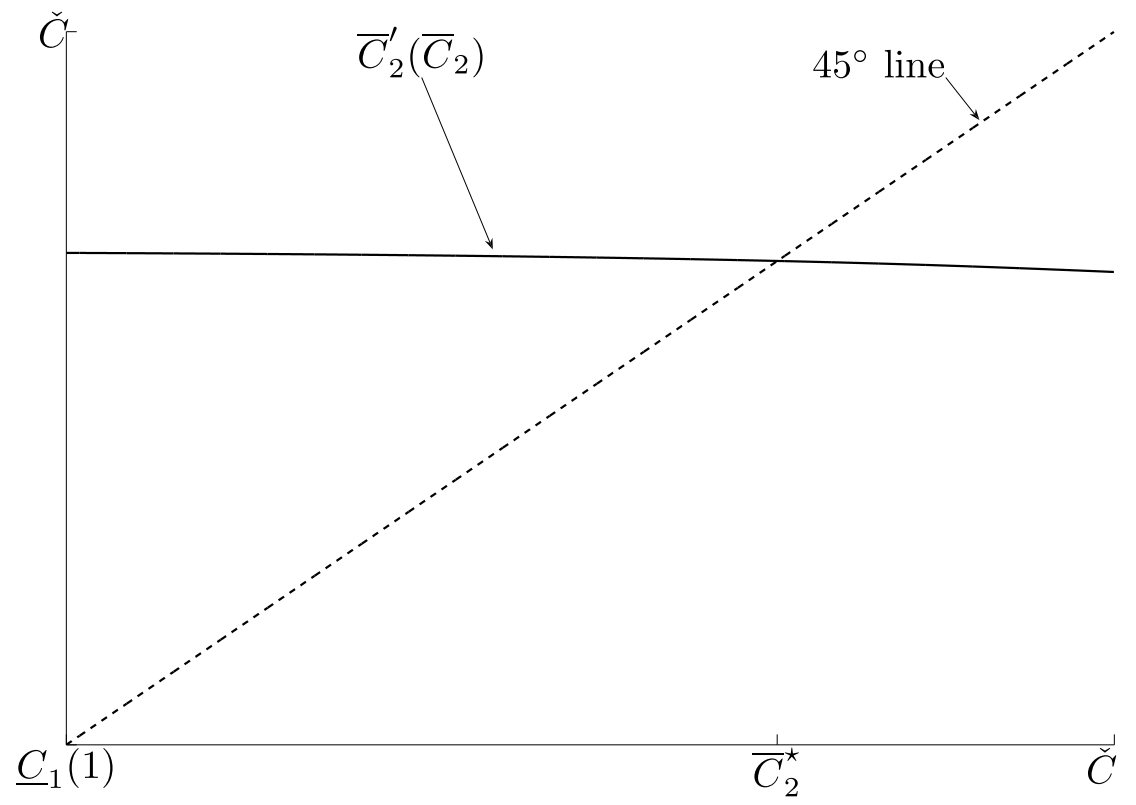

Figure 5: Equilibrium Determination of $\bar{C}_{2}^{\star}$ in the FIFO Example

next period is identical to a similarly situated incumbent monopolist. Hence, the value of entering in this case is $v(0, C, 1)$. If instead $C>\bar{C}_{2}^{\star}$, then this firm expects to become a duopolist following the next period if $C$ remains unchanged. It is possible that the resulting payoff could fall below $\varphi(1)$, in which case equilibrium entry rule would not follow a threshold rule. In the following, we assume that this does not occur.

Assumption 3. The following inequality holds.

$$
\beta\left((1-\lambda)\left(\bar{C}_{2}^{\star} \pi(1)-\kappa+v\left(1, \bar{C}_{2}^{\star}, 1\right)\right)+\lambda \widetilde{v}(0,1)\right) \geq \varphi(1)
$$

Because $\varphi(1)$ played no role in the construction of the left-hand side of this inequality, it is a positive upper bound on $\varphi(1)$. It guarantees that there is a single value of $C$ which equates the payoff to entry as a monopolist with $\varphi(1)$. This is the monopoly entry threshold, $\bar{C}_{1}(0)$.

Finally, consider raising $\varphi(2)$ while holding $\varphi(1)$ constant. Increasing $\varphi(2)$ directly increases the function $\bar{C}_{2}^{\prime}(\cdot)$, so it also weakly increases $\bar{C}_{2}^{\star}$. This in turn raises the rank 1 value function's monopoly branch $\left(v_{S}(0, C, 1)\right)$ and leaves its duopoly branch $\left(v_{S}(1, C, 1)\right)$ unchanged. From this, Proposition 5 follows. 